\title{
PENDALAMAN KONSEP FISIKA MENGGUNAKAN ALAT PERAGA BERBASIS MIKROKONTROLER PADA SISWA SMA
}

\author{
Nurul Qomariyah"1), Rahadi Wirawan"1), Suhayat minardi'1), Siti Alaa'1), \\ I Gusti Ngurah Yudi Handayana1) \\ 1)Program Studi Fisika, FMIPA, Universitas Mataram, Mataram, NTB, Indonesia \\ Corresponding author : Nurul Qomariyah \\ E-mail : nurulqomariyah@unram.ac.id
}

\begin{abstract}
ABSTRAK
Kegiatan pengabdian ini bertujuan untuk memberikan pendalaman konsep dasar fisika melalui metode praktikum atau eksperimen menggunakan alat peraga serta pengenalan mikrokontroler untuk pembuatan alat peraga sederhana. Tempat pelaksanaan pengabdian di Ponpes Darul Aminin NW Aikmual Lombok Tengah. Kegiatan ini dibagi menjadi beberapa tahapan yang pertama pemberian materi mengenai pendalaman konsep-konsep dasar fisika dan materi pengenalan mikrokonroler sebagai komponen alat peraga, tahapan kedua Tim PKM mendemonstrasikan penggunaan alat peraga pada materi gerak Jatuh (GJB), bandul matematis, kinematika, dan konsep konversi energi, tahapan terakhir yaitu tim PKM memberikan kesempatan peserta untuk mencoba langsung menggunakan alat peraga yang disediakan. Kegiatan ini memberikan manfaat dalam meningkatkan pemahaman konsep fisika pada siswa melalui metode eksperimen. Dengan metode ini siswa juga lebih aktif dan dapat melihat langsung fenomena fisika yang terjadi melalui pengamatan. Keterbatasan alat peraga di sekolah dapat disiasati dengan pembuatan set eksperimen berbasis mikrokontroler yang penggunaanya sangat mudah dan luas. Pembelajaran menggunakan metode eksperimen ini diharapkan dapat meningkatkan kualitas pembelajaran di sekolah.
\end{abstract}

Kata kunci: alat peraga; metode eksperimen; mikrokontroler.

\begin{abstract}
This service activity aims to understand the basic concepts of physics through practicum or experimental methods using props and microcontroller introduction training for making simple props. Implementation of community service at Darul Aminin Islamic Boarding School, NW Aikmual, Central Lombok. This activity is divided into several stages. The first is providing material regarding the deepening of physics concepts and material for the introduction of microcontrollers as props components, the second stage of the PKM Team which uses props on Fall motion material (GJB), mathematical pendulum, kinematics, and concepts conversion of energy inthe last stage, the PKM team, allowed participants to try directly using the tools provided. This activity provides benefits in improving students' understanding of physics concepts through the experimental method. With this method, students are also more active and can see first hand the physical phenomena that occur through observation. The limitations of teaching aids in schools can be overcome by making microcontroller-based experimental sets that are very easy and widely used. Learning using the experimental method is expected to improve the quality of learning in schools.
\end{abstract}

Keywords: props; experimental method; mikrokontroler.

\section{PENDAHULUAN}

Paradigma yang terbangun selama ini pada siswa terhadap pelajaran IPA atau sains khususnya fisika adalah pelajaran yang sulit dengan banyak hafalan rumus dan teori sehingga siswa merasa bosan. Salah satu faktornya adalah penyampaian konsep fisika yang hanya diberikan dalam menyampaian materi dalam kelas. Padahal fisika sebagai salah satu cabang IPA, mempelajari dan menganalisis secara kuantitatif gejala atau proses alam dan sifat zat serta penerapannya. Ada banyak pilihan metode pembelajaran fisika inovatif untuk membelajarkan konsep fisika yang konkret namun belum banyak dipraktikkan oleh para guru di kelas, misalnya metode eksperimen dan demonstrasi menggunakan alat peraga (Azhar, 2003; Sriyanti et al., 2018). Menurut Hani (Hani, 2011) metode pembelajaran berbasis eksperimen perlu dikembangkan sehingga dapat meningkatkan peran guru untuk menjalankan fungsinya sebagai fasilitator dan mediator pembelajaran yang efektif dan efisien. Selain itu perlu dikembangkan pemanfaatan alat eksperimen fisika dalam metode pembelajaran agar dapat 
dijadikan sebagai model dalam pembelajaran berbasis eksperimen yang lebih menarik dan mudah dipahami untuk menanamkan pemahaman konsep yang benar pada siswa. Hal tersebut selaras dengan kurikulum 2013 juga menuntut pengembangan secara seimbang softskill dan hardskill peserta didik.

Selaras dengan tuntutan Peraturan Menteri Pendidikan Nasional Nomor 22 Tahun 2006 tentang Standar Isi (SI) dan Peraturan Menteri Pendidikan Nasional Nomor 23 Tahun 2006 Tentang Standar Kompetensi Lulusan (SKL) (Departemen Pendidikan Nasional, 2006b, 2006a; Depdikbud, 2013), pembelajaran IPA harus secara proporsional mengembangkan kemampuan deklaratif dan kemampuan prosedural maka fungsi laboratorium tidak hanya sekedar untuk kegiatan praktikum saja tetapi merupakan bagian dari kegiatan pembelajaran IPA. Penggunaan alat peraga dalam pembelajaran IPA dapat dioptimalkan dalam proses pembelajaran. Menurut Subekti (Subekti \& Ariswan, 2016) metode eksperimen merupakan cara penyajian mata pelajaran dimana siswa secara aktif mengalami dan membuktikan sendiri apa yang sedang dipelajarinya sehingga secara total dilibatkan dalam melakukan sendiri, membuktikan dan menarik kesimpulan sendiri tentang suatu objek, atau fenomena fisis sehingga cocok untuk diaplikasikan pada pembelajaran IPA khusunya Fisika.

Keterbatasan alat peraga fisika di disekolah merupakan salah satu kendala tidak optimalnya penggunaan metode eksperimen pada proses penyampain konsep fisika. Kendala tersebut dapat diatasi apabila memiliki kemampuan dalam membuat suatu peralatan dan men-setup suatu eksperimen sederhana. tidak hanya menggunakan alat peraga yang sudah ada akan tetapi dapat memodifikasi alat tersebut untuk kebutuhan dalam pembelajarann mengikuti perkembangan teknologi untuk menghasilkan nilai tambah pada anak didik. Perkembangan di bidang instrumentasi saat ini seperti sensor, mikrokontroler, dan komputer memungkinkan untuk membangun suatu instrumen sederhana yang akurat, dan portable (Kadir, 2013). Selain itu juga didukung oleh keberadaan dan ketersediaan sensor di pasaran khususnya di Indonesia. Hal penting yang perlu dipersiapkan adalah kemampuan dalam mengkombinasikan sensor-sensor dengan modul instrumen serta mengoperasikannya untuk diaplikasikan dalam membangun suatu eksperimen sederhana seperti halnya mengaplikasikan sensor infrared dan Arduino Uno untuk alat peraga sederhana gerak jatuh bebas (Qomariyah \& Wirawan, 2018), pengaplikasian sensor ultrasonik untuk mendeteksi frekuensi getaran benda (Wirawan et al., 2012).

Perguruan tinggi khususnya Universitas Mataram melalui salah kegiatan tridharmanya yaitu pengabdian kepada masyarakat dapat membantu mentransformasi kemampuan, pengalaman dan mengimplementasikan hasilhasil penelitian dari bidang minat instrumentasi dan Biofisika Fakultas Matematika dan IImu Pengetahuan Alam (FMIPA) Universitas Mataram untuk mengembangkan beberapa peralatan-peralatan praktikum sederhana berbasis Mikrokontroler. Oleh karenanya, melalui kegiatan pengabdian kepada masyarakat akan dilakukan suatu kegiatan penguatan kemampuan eksperimen fisika melalui pemanfaatan mikrokontroler di Ponpes ponpes Darul Aminin NW Aikmual Lombok Tengah

\section{METODE}

Kegiatan ini dilaksanakan tanggal 30 September 2020 di di ponpes Darul Aminin NW Aikmual Lombok Tengah dengan sasaran dalam kegiatan adalah siswa-siswa MA. DasarDalam kegiatan ini di bagi dalam beberapa tahapan untuk mendapatkan tujuan yang diinginkan.Tahapan pertama yaitu pendalaman konsep-konsep dasar fisika dan pengenalan dasar-dasar Mikrokontroler Arduino Uno yang diberikan secara direct instruction. Pada tahapan pendalaman konsep fisika, konsep fisika disampaikan dengan sesederhana mungkin, tidak perlu menghafal banyak rumus akan tetapi menekankan pada problem solving dari persoalan fisis, contohnya untuk gerak paraboba maka digambarkan diagram bebasnya dan dilihat parameter yang saling mempengaruhi. Pada tahapan ini juga di berikan pengetahuan sebagai komponen dasar alat peraga. Pada tahapan kedua yaitu demonstrasi set eksperimen yang telah dibuat menggunakan modul Mikrokontroler Arduino Uno yaitu pada materi Gerak Jatuh Bebas (GJB), bandul matematis, kinematika, dan konsep energy (konversi energi panas menjadi gerak dan energy listrik). Tahapan yang terakhir adalah percobaan langsung oleh peserta dimana peserta dapat melakukan pengamatan dan melihat konsep aplikasi mikrokontroler untuk pembuatan set eksperimen. Evaluasi kegiatan ini dilakukan untuk mengetahui efektifitas kegiatan yang dilakukan. Evaluasi proses berkaitan dengan kehadiran peserta, semangat mengikuti kegiatan, dan kerja sama, evaluasi proses juga juga dinilai terhadap aktivitasdan sikap positif yang ditunjukkan peserta selama kegiatan berlangsung. 


\section{HASIL DAN PEMBAHASAN}

Kegiatan pengabdian bertujuan memberikan pendalaman konsep dasar fisika melalui metode praktikum atau eksperimen menggunakan alat peraga serta pengenalan mikrokontroler sebagai komponen dasar untuk pembuatan alat peraga sederhana. Peserta sangat antusias selama pelaksanaan kegiatan. Tahapan pertama dalam kegiatan PKM ini yaitu pemberian materi mengenai konsep-konsep dasar fisika dan pengenalan dasar-dasar Mikrokontroler Arduino Uno seperti yang ditunjukkan pada Gambar 1.

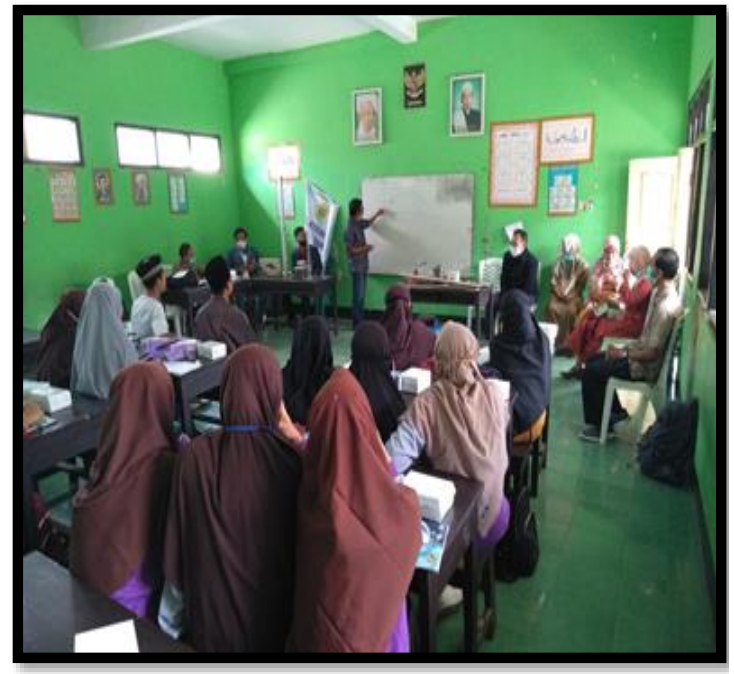

(a)

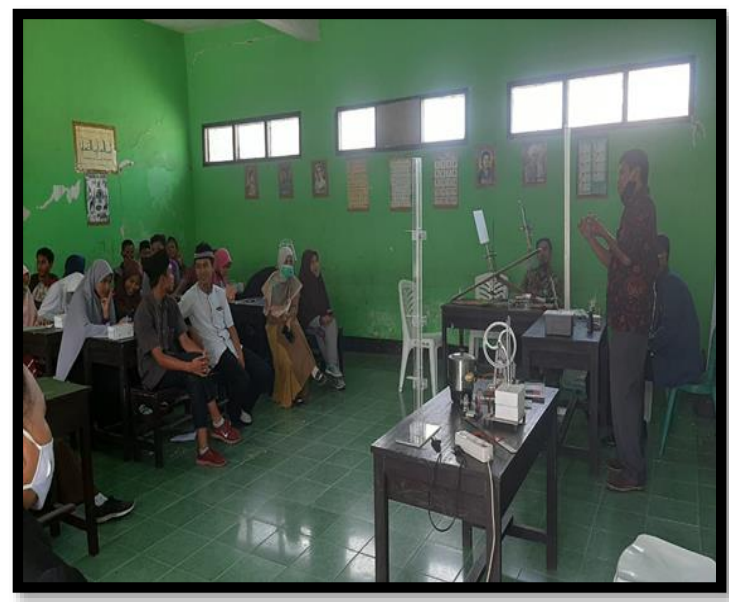

(b)

Gambar 1. Pemberian materi (a) konsep dasar fisika (b) prinsip modul mikrokontroler Arduino Uno.

Berdasarkan analisis terhadap hasil pantauan pelaksanaan kegiatan pengabdian, didapatkan beberapa fakta bahwa secara umum para siswa mengatakan bahwa konsep fisika yang diterima selama ini diberikan secara metode konvensional di dalam kelas dengan banyak teori dan hafalan rumus-rumus sehingga siswa merasa kesulitan menerima konseptual secara utuh. Dalam kegiatan ini Tim PKM pada gamabr 1(a) mencoba memberikan dasar-dasar konsep fisika secara sederhana dan mendalam agar siswa tidak menghafal formula /rumus-rumus fisika tetapi mengerti secara konseptual. Pemberian materi mengenai konsep-konsep dasar mikrokontroler juga diberikan, diharapkan para peserta memiliki gambaran pembuatan set eksperimen fisika menggunakan mikrokontroler.
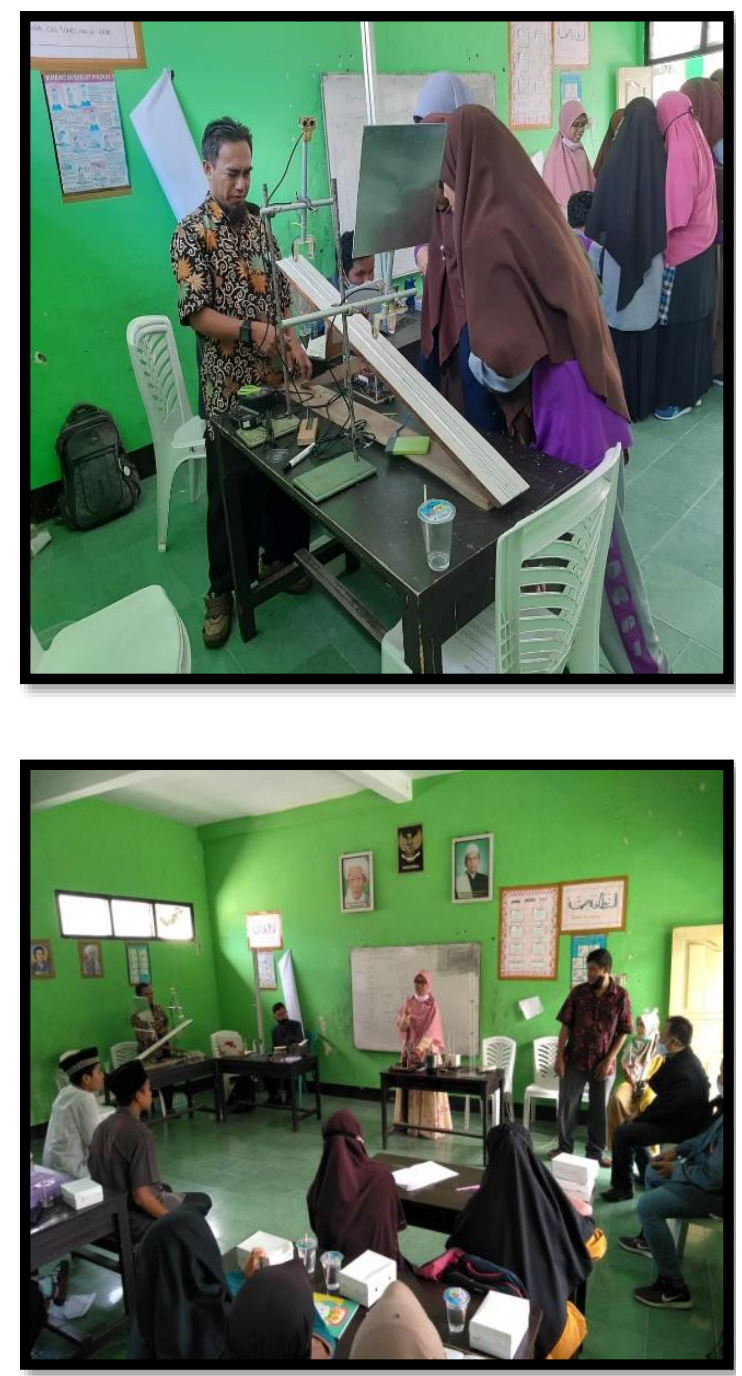

Gambar 2. Demonstrasi Penggunaan set eksperimen.

Gambar 2 memperlihatkan Tim PKM mendemonstrasikan alat peraga secara bergantian dari beberapa materi yaitu Gerak Jatuh Bebas (GJB), bandul matematis, kemudian materi mekanika, dan materi konfersi energi panas menjadi energi gerak dan Listrik. Kegiatan simulasi ini diawali dengan mengenalkan nama-nama dan fungsi alat-alat pada tiap komponen percobaan, dan fungsi modul mikrokontroler pada rangkaian percobaan, kemudian mensimulasikan 
eksperimen dan pengambilan data-data untuk pengamatan serta menelaah konsep fisika yang terjadi pada fenomena tersebut. Hal ini dimaksutkan untuk memberikan wawasan kepada peserta didik bahwa penanaman konsep dasar fisika dengan menggunakan alat peraga dapat langsung memperlihatkan fenomena yang terjadi sehingga konsep fisika dapat mudah lebih difahami dan terbatasnya alat peraga di sekolah bisa disiasati menggunakan mikrokontroler yang pembuatannya sangat sederhana dan dapat dipergunakan secara luas.

Tahapan selanjutnya adalah memberikan kesempatan pada peserta untuk mencoba langsung alat peraga dan melakukan pengamatan, serta peserta dibebaskan untuk bertanya kepada tim PKM mengenai materi maupun alat peraga yang sedang dicoba seperti terlihat pada Gambar 3.

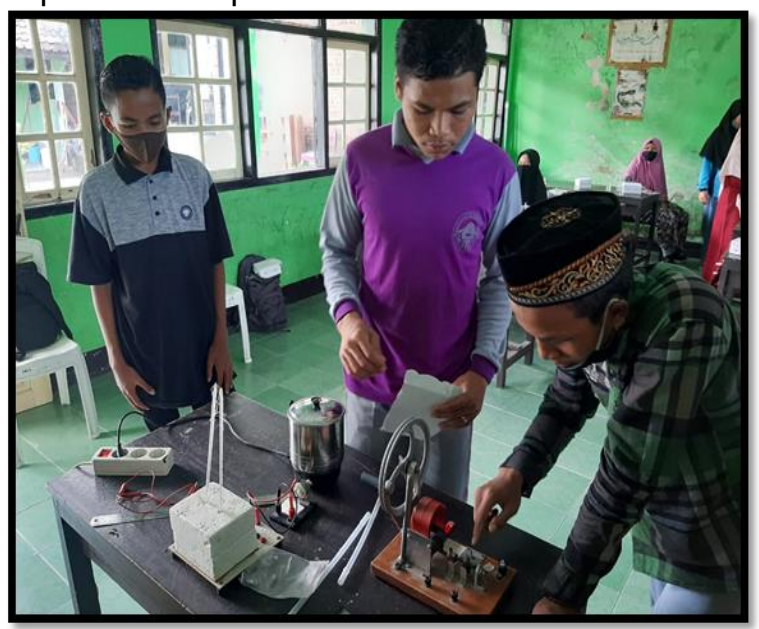

Gambar 3. Peserta mencoba menggunakan alat peraga

Pada Gambar 3 terlihat para peserta sangat antusias dalam mencoba alat peraga secara bergiliran. hal ini juga mampu meningkatkan motivasi siswa dalam belajar Sains. Salah satu model pembelajaran yang cocok untuk mempelajari fisika adalah model melalui metode eksperimen. Penyajian materi melalui metode eksperimen dapat memotivasi siswa secara aktif mengalami dan membuktikan sendiri apa yang sedang dipelajarinya. Melalui metode ini siswa secara total dilibatkan dalam melakukan sendiri, membuktikan dan menarik kesimpulan sendiri tentang suatu objek, keadaan atau proses tertentu. Metode eksperimen melatih siswa untuk merekam semua data fakta yang diperoleh melalui hasil pengamatan dan bukan data opini hasil rekayasa pemikiran.

Kegiatan PKM ini dimaksudkan agar siswa mampu mempertajam konsep fisika melalui pengamatan sehingga siswa diharapkan dapat mencari informasi, data, fakta yang diperlukan melalui kegiatan pengamatanpengamatan atau kegiatan eksperimen. melalui metode eksperimen juga diharapkan dapat meningkatkan keterampilan proses sains yaitu kemampuan dalam mengamati, menghitung, mengukur, mengklasifikasikan, menemukan hubungan, membuat prediksi, melakukan penelitian, mengumpulkan dan menganalisis data, menginterpretasikannya sehingga penguatan konsep fisika dapat diperoleh secara utuh. Mengembangkan keterampilan proses sangat penting untuk membangun pemahaman tentang dunia dan pembelajaran sains, misalnya: ide-ide dan konsep-konsep bagaimana energi panas dapat dikonversi menjadi energi gerak dan energi listrik seperti yang telah disampaikan pada saat kegiatan berlangsung.

\section{SIMPULAN DAN SARAN Simpulan}

Kegiatan PKM dengan tema pemanfaatan set eksperimen berbasis mikrokontroler dalam pembelajaran fisika di ponpes Darul Aminin NW Aikmual Lombok Tengah memberikan manfaat dalam meningkatkan pemahaman konsep fisika pada siswa melalui metode eksperimen. Dengan metode ini siswa lebih aktif dan dapat melihat langsung fenomena fisika yang terjadi melalui serangkaian pengamatan. Minimnya alat peraga di sekolah dapat disiasati dengan pembuatan set eksperimen berbasis mikrokontroler yang penggunaanya sangat mudah dan luas. Pembelajaran menggunakan metode eksperimen ini diharapkan dapat meningkatkan kualitas pembelajaran di sekolah.

\section{Saran}

Melihat antusiasme siswa dalam mengikuti kegiatan demonstrasi set eksperimen berbasis mikrokontroler ini serta manfaatnya yang sangat besar terutama dalam meningkatkan tingkat pemahaman siswa, maka diharapkan kegiatan ini memiliki keberlanjutan di masa-masa mendatang demi tercapainya kualitas pendidikan yang lebih baik, utamanya di daerah Provinsi Nusa Tenggara Barat.

\section{UCAPAN TERIMAKASIH}

Penulis mengucapkan terima kasih kepada Universitas Mataram atas dukungannya melalui Pengabdian Kepada Masyarakat pendanaan BLU (PNBP) 2020.

\section{DAFTAR RUJUKAN}

Azhar, A. (2003). Media pengajaran. Raja Grafindo Persada.

Departemen Pendidikan Nasional. (2006a). 
Kurikulum Tingkat Satuan Pendidikan Sekolah Dasar Pelajaran IPA SD/MI. Depdiknas.

Departemen Pendidikan Nasional. (2006b). Standar Kompetensi Mata pelajaran Fisika. Pusat Kurikulum.

Depdikbud. (2013). Dokumen Kurikulum 2013. Depdikbud.

Hani, A. R. (2011). Pembelajaran Fisika Berbasis Eksperimen: Kasus Perbedaan Pemahaman Konsep Pokok Bahasan Gerak Gaya dan Energi Pada Siswa Kelas X Sma Pembangunan 3 Ponjong Gunungkidul Yogyakarta. Prosiding Seminar Nasional Penelitian, Pendidikan Dan Penerapan MIPA, Fakultas MIPA, Universitas Negeri Yogyakarta.

Kadir, A. (2013). Panduan Praktis Mempelajari Aplikasi Mikrokontroler dan Penggunaannya menggunakan Arduino. Penerbit Andi.

Qomariyah, N., \& Wirawan, R. (2018). Aplikasi sensor Infrared dan Arduino Uno Untuk Alat Peraga Sedehana Gerak Jatuh Bebas. Prosiding PKM-CSR.

Sriyanti, I., Siahaan, S. M., Muslim, M., Sudirman, \& Ariska, M. (2018). Pendampingan Pembuatan Alat Peraga Ipa Sederhana Sebagai Upaya Untuk Menciptakan Karya Inovatif Bagi Guru- Guru Ipa Smp Se-Kota Lubuklinggau. Jurnal Inovasi Dan PEmbelajaran Fisika (JIPF), 5(2).

Subekti, Y., \& Ariswan, A. (2016). Pembelajaran Fisika dengan Metode Eksperimen untuk Meningkatkan Hasil Belajar kognitif dan Keterampilan Proses Sains. Jurnal Inovasi Pendidikan Ipa, 2(2).

Wirawan, R., Djamal, M., Hartono, A., Sanjaya, E., Indrasari, W., \& Ramli. (2012). Aplikasi Sensor Ultrasonik Untuk Pengukuran Getaran Frekuensi Renda. Prosiding Simposium Nasional Inovasi Pembelajaran Dan Sains 2012. 